\title{
CONSIDERAÇÕES SOBRE AS NORMATIVIDADES CONSTITUCIONAIS E INFRACONSTITUCIONAIS ACERCA DO MEIO AMBIENTE SADIO E SUA INTERAÇÃO COM O SER HUMANO
}

\section{CONSIDERATIONS ON CONSTITUTIONAL AND INFRACONSTITUTIONAL NORMATIVITIES ABOUT HEALTHY ENVIRONMENT AND THEIR INTERACTION WITH THE HUMAN BEING}

Thiago Jordace ${ }^{1}$

\section{Resumo}

A percepção da necessidade de preservação ambiental foi construída com muito vagar ao longo dos tempos, existindo uma dicotomia de marcos históricos em relação ao âmbito internacional e o brasileiro, pois a experiência nacional teve início apenas com a data do descobrimento. Entretanto, essa situação dúplice não separa a convergência de construção paulatina de necessária preservação construída ao longo da história. A aproximação dessa consciência pode ser verificada quando da análise normativa das constituições mundiais, da carta brasileira vigente e das normas infraconstitucionais, algo interessante porque os países sofreram transformações históricas diferentes, mas chegaram ao mesmo ponto: constitucionalização da tutela jurídica ambiental.

Palavras-chave: Direito Ambiental Constitucional, transformações históricas normativas, meio ambiente.

\section{Abstract}

The perceived need for environmental preservation was built very slowly over time and there is a dichotomy landmarks in relation to the international context and the Brazilian as the national experience began only with the date of the discovery. However, this dual situation does not separate the convergence of gradual building of necessary preservation built throughout history. The approach of this consciousness can be checked when the normative analysis of world constitutions, the current Brazilian letter and infra-constitutional norms, something interesting because countries have experienced different historical transformations, but arrived at the same point: constitutionalization of environmental legal protection.

Keywords: Constitutional Environmental Law, normative historical transformations, environment.

\footnotetext{
${ }^{1}$ Doutorando em Direito da Cidade pela UERJ, Mestre em Direito Penal pela UERJ, Bacharel em Direito pela UFRJ, professor universitário. E-mail: thiagojordace@hotmail.com
} 


\section{INTRODUÇÃO}

Por ser uma área dinâmica do saber, o Direito será diferente dependendo da época histórica e da diversidade cultural de cada sociedade. Em determinado povo, um direito pode ser tido como fundamental e em outro este pode não ter essa qualidade².

Nos tempos em que vigorava o Direito Romano, o meio ambiente era considerado res nulius $^{3}$. Em outras palavras, o que hoje se entende como um bem fundamental, naquela época era considerado um objeto sem dono. Não havia interesse em preservar algo que pertencia a ninguém. Além disso, havia a certeza de que a natureza era infinita e estava à disposição de todos para ser apropriada e usada de qualquer forma ${ }^{4}$.

Já na idade moderna, passou-se a considerar o meio ambiente um bem de uso comum do povo. Apesar de ainda não ser considerada coisa pública, a natureza passou a ser objeto de tutela em razão da intensa exploração da matéria-prima natural. Isto se deveu ao fato de que o processo de industrialização demandou maior utilização dos recursos naturais, de forma a atender aos avanços da tecnologia que surgia ${ }^{5}$. A mecanização do processo produtivo fez a humanidade perceber a limitação dos referidos recursos: a ideia anterior de reservas naturais ilimitadas foi deixada de lado, pois houve o início da ameaça de escassez de bens coletivos ${ }^{6}$.

A percepção surgida naquela época perpetuou-se até a presente data, e, atualmente, vivese uma época de intensa preocupação com os recursos naturais. Existem encontros internacionais específicos para o debate acerca do meio ambiente, a exemplo da Eco 92. A natureza não é mais res nulius ou mero bem público de cada Estado7: ela é agora considerada um direito fundamental universal, patrimônio da humanidade, constitucionalmente tutelado.

Entretanto, a necessidade de preservação foi verificada tardiamente, com diversas advertências e profecias pretéritas, pautadas em estudos científicos que, hoje, são uma realidade. Não se trata mais de uma ideologia ou um mero estilo de vida manutenção da natureza, mas um diferencial se haverá perpetuação da vida humana no planeta ou não. Já não existe mais margem

\footnotetext{
2 BOBBIO, Norberto. A era dos direitos. Rio de Janeiro: Campus Elsevier, 1992.

3 "RES NULLIUS. É a coisa de ninguém ou coisa sem dono.

A res nullius, entretanto, traz sentido amplo, pois que tanto atinge as coisas extra commercium (fora do comércio), como as res derelictae (coisas abandonadas).

Embora sem dono, há res nullius suscetível de apropriação. E há res nullius inapropriável, por ser res publicae". (SILVA, De Plácido de. Vocabulário jurídico: volume 4. 5. ed., Rio de Janeiro: Forense, 1978).

${ }^{4}$ FARIAS, Paulo José Leite. Competência federativa e proteção ambiental. Porto Alegre: Sérgio Antônio Fabris.

${ }^{5}$ LoC. cit.

${ }^{6}$ Loc. cit.

${ }^{7}$ SÉGUIN, Elida. Direito ambiental: nossa casa planetária. 2. ed. Rio de Janeiro: Forense, 2002, p. 16
} 
de escolha para preservar ou não, deve-se manter o meio ambiente de forma a desenvolver a tecnologia e a economia com sustentabilidade, em harmonia com a natureza.

\section{ALGUMAS PREVISÕES NORMATIVAS CONSTITUCIONAIS ESTRANGEIRAS ACERCA DO MEIO AMBIENTE}

É certo dizer que o Homem de ontem tinha mais margem de liberdade para decisões em relação ao de hoje, pois não há mais como adiar políticas preservacionistas para manutenção das presentes e futuras gerações. Caso não haja uma salvaguarda mundial do meio ambiente, fenômenos naturais ocasionados pela degradação serão mais constantes e intensos, objetos de contato em todos os sentidos - nos dizeres de Carlos Roberto Siqueira Castro ${ }^{8}$ :

"(...) pela visão dramática e apocalíptica das sequelas da poluição dos mares e dos rios e da desertificação das florestas; pela audição dos decibéis ensurdecedores; pelo olfato do monóxido de carbono e dos odores nauseantes dos centros urbanos e industriais; pelo sabor acre da água cada vez mais clorodificada, das verduras com doses crescentes de agrotóxicos e dos alimentos enlatados e conservados à custa da química cancerígena; pela sensação do calor insuportável e das alterações climáticas, não raro catastróficas, resultantes da destruição da camada de ozônio, que provoca o esquentamento do planeta e do degelo das calotas polares. E isto sem esquecer a perspectiva de pânico total e de implosão repentista de todas as formas de vida, o que deixou de ser fantasia futurista em face do potencial destruidor da guerra química e da hecatombe nuclear, tornada factível após o genocídio atômico de Nagasaki e Hiroshima.".

Sob a ótica ambiental, é certo dizer que o âmbito de liberdade de escolha para cumprimento de satisfações pessoais eram maiores que os de hoje, pois, no presente, não há margem plena de decisões degradantes ou não, há tão somente um objetivo limitado de decidir: preservação da natureza. Pode parecer um pouco radical a posição do autor, mas a acumulação de poluentes de séculos e séculos não sumiram, como se disse: houve uma cumulação de detritos, ocorrendo um total desequilíbrio do planeta - não mais invisível - mas perceptível com facilidade em qualquer parte do globo.

Nesse contexto de degradação mundial, surge o Direito Ambiental ${ }^{9}$ como um conjunto de regras e princípios jurídicos disciplinadores das condutas efetivas ou potencialmente lesivas ao meio ambiente, firmando-se uma tendência a partir da década de setenta como tema, com bem

\footnotetext{
${ }^{8}$ CASTRO, Carlos Roberto Siqueira. A Constituição aberta e os direitos fundamentais, p. 698.

${ }^{9}$ Direito Ambiental "(...) é o complexo de princípios e normas coercitivas reguladoras das atividades humanas que, direta ou indiretamente, possam afetar a sanidade do ambiente em sua dimensão global, visando à sua sustentabilidade para as presentes e futuras gerações." (MILARÉ, Édis. Direito do Ambiente. São Paulo: Revista dos Tribunais, 2001, p. 109)
} 
jurídico específico de proteção constitucional ${ }^{10}$. Eis alguns exemplos constitucionais de previsão ambiental ${ }^{11}$ :

Portugal - Constituição de $1976^{12}$ :

"Artigo 66. - - Ambiente e qualidade de vida:

1. Todos têm direito a um ambiente de vida humano, sadio e ecologicamente equilibrado e o dever de o defender.

2. Para assegurar o direito ao ambiente, no quadro de um desenvolvimento sustentável, incumbe ao Estado, por meio de organismos próprios e com o envolvimento e a participação dos cidadãos:

a. $\quad$ Prevenir e controlar a poluição e os seus efeitos e as formas prejudiciais de erosão;

b. Ordenar e promover o ordenamento do território, tendo em vista uma correcta localização das actividades, um equilibrado desenvolvimento sócio-económico e a valorização da paisagem;

c. Criar e desenvolver reservas e parques naturais e de recreio, bem como classificar e proteger paisagens e sítios, de modo a garantir a conservação da natureza e a preservação de valores culturais de interesse histórico ou artístico;

d. Promover o aproveitamento racional dos recursos naturais, salvaguardando a sua capacidade de renovação e a estabilidade ecológica, com respeito pelo princípio da solidariedade entre gerações; Promover, em colaboração com as autarquias locais, a qualidade ambiental das povoações e da vida urbana, designadamente no plano arquitectónico e da protecção das zonas históricas;

e. Promover a integração de objectivos ambientais nas várias políticas de âmbito sectorial;

f.Promover a educação ambiental e o respeito pelos valores do ambiente;

Assegurar que a política fiscal compatibilize desenvolvimento com proteç̧ão do ambiente e qualidade de vida.".

"Artigo 81..: Incumbências prioritárias do Estado - Incumbe prioritariamente ao Estado no âmbito económico e social:

a. Promover o aumento do bem-estar social e económico e da qualidade de vida das pessoas, em especial das mais desfavorecidas, no quadro de uma estratégia de desenvolvimento sustentável;

(..)

j. Criar os instrumentos jurídicos e técnicos necessários ao planeamento democrático do desenvolvimento económico e social;

I. Assegurar uma política científica e tecnológica favorável ao desenvolvimento do país;

${ }^{10}$ CASTRO, Carlos Roberto Siqueira. Op. cit., p. 700.

${ }^{11}$ A escolha das constituições dos países a seguir foi por intermédio dos estudos de Carlos Roberto Siqueira Castro, ou seja, por amostragem; não foram apresentadas outras legislações estrangeiras neste ponto por não ser o objetivo específico do trabalho, o qual demandaria um estudo pormenorizado em longas páginas.

12 Constituição da República Portuguesa de 1976, disponível no site:

< http://www.parlamento.pt/Legislacao/Paginas/ConstituicaoRepublicaPortuguesa.aspx> 
m. Adoptar uma política nacional de energia, com preservação dos recursos naturais e do equilíbrio ecológico, promovendo, neste domínio, a cooperação internacional;

n. Adoptar uma política nacional da água, com aproveitamento, planeamento e gestão racional dos recursos hídricos."

"Artigo 90.o - Objectivos dos planos: Os planos de desenvolvimento económico e social têm por objectivo promover o crescimento económico, o desenvolvimento harmonioso e integrado de sectores e regiões, a justa repartição individual e regional do produto nacional, a coordenação da política económica com as políticas social, educativa e cultural, a defesa do mundo rural, a preservação do equilíbrio ecológico, a defesa do ambiente e a qualidade de vida do povo português." (grifos do autor).

A constituição portuguesa apresenta uma proteção holística do bem jurídico meio ambiente, ou seja, não o prevê tão somente como um meio para um determinado fim, mas um objetivo em si mesmo, importante por si só. Não é de se surpreender a decisão do poder constituinte lusitano, pois Portugal tem preocupação histórica-legislativa com a proteção da natureza desde o século XIV.

A História portuguesa em relação ao território luso é bem diferente quando comparado ao espaço brasileiro, pois desde o século XIV há legislações avançadas de proteção ambiental, apresentando um ordenamento jurídico protetivo à natureza. É o que indica MAGALHÃES ${ }^{13}$, dizendo que Portugal: (...) já possuía uma vasta legislação de proteção ambiental. Ann Helen Wainer afirma que essa legislação era bastante evoluída, destacando algumas disposições relevantes. Por exemplo, o corte deliberado de árvores frutíferas foi proibido em 12 de março de 1393.".

Também em relação ao mesmo período histórico, a proteção ambiental portuguesa abrangia também a fauna, nos dizeres de WAINER ${ }^{14}$ : "(...) a preocupação com as aves originou uma previsão instituída pelo rei D. Diniz, em 9 de novembro de 1326, que equiparava o furto das aves, para efeitos criminais, a qualquer outra forma de furto.". A mesma legislação apresentava previsão de sanção pecuniária ao sujeito ativo do delito de furto de animais, objetivando reparar a vítima pela perda do patrimônio. A norma ia além: apresentava uma estimativa de valor para determinada espécie de aves - não há dúvidas que era uma norma bastante evoluída para a época.

Analisando a atual constituição portuguesa, há alguns destaques merecedores de análise: o artigo 66, 1, apresenta ser direito de todos um meio ambiente sadio e equilibrando, sendo dever

\footnotetext{
13 MAGALHÃES, Juraci Perez. A Evolução do Direito Ambiental no Brasil. 2 ed. São Paulo: Editora Juarez de Oliveira, 2002, p. 88.

14 WAINER, Ann Helen. Legislação Ambiental Brasileira: Evolução Histórica do Direito Ambiental. Revista de informação legislativa, v.30, no 118, p. 191-206, abr./jun. de 1993.
} 
de todos sua preservação, ou seja, não é apenas os portugueses que detém o direito a gozar e fruir do bem jurídico, mas toda a humanidade. Além disso, também toda a comunidade mundial tem o dever de zelar por sua manutenção.

Outro destaque merecedor de comentários é o artigo 66, 2, o qual prevê o desenvolvimento sustentável como objetivo do Estado português, ou seja, o dispositivo deixa clara a necessidade de progresso econômico e tecnológica em harmonia com o meio ambiente. O povo português deve sempre ater à manutenção da natureza para qualquer empreendimento potencialmente ou efetivamente poluidor. Entretanto, o desenvolvimento não deve parar para manutenção total do bem jurídico português em comento: não é isso. Como já fora apresentado em linhas pregressas, o desenvolvimento sustentável deve trazer medidas de preservação e/ou compensatórias para a natureza, objetivando perpetuar o progresso da nação; em outras palavras, é o desenvolvimento suficiente para atender a demanda da população presente sem ceifar as necessidades das gerações futuras, mantendo os recursos e perpetuando a vida.

Considerando a Espanha, verifique os dizeres da Constitución española de $1978^{15}$ - Artículo 45:

1. $\quad$ "1. Todos tienen el derecho a disfrutar de un medio ambiente adecuado para el desarrollo de la persona, así como el deber de conservarlo.

2. Los poderes públicos velarán por la utilización racional de todos los recursos naturales, con el fin de proteger y mejorar la calidad de la vida y defender y restaurar el medio ambiente, apoyándose en la indispensable solidaridad colectiva.

3. Para quienes violen lo dispuesto en el apartado anterior, en los términos que la ley fije se establecerán sanciones penales o, en su caso, administrativas, así como la obligación de reparar el daño causado." (grifos do autor).

A constituição espanhola também previu o meio ambiente como bem jurídico holístico, apresentando um objetivo preservacionista também conjunto entre o Estado e a sociedade mundial, bem como um direito da pessoa desfrutá-lo - artículo 45, 1. Portanto, é uma disposição parecida com as constituições brasileira e portuguesa.

Há disposição específica no artículo 45, 2, do dever do Estado, em parceria com a sociedade, de preservação e utilização racional dos recursos naturais. É uma disposição importante por apresentar uma obrigação clara de responsabilidade ambiental para todos, pois somente os poderes públicos não conseguem tutelar a natureza: é dever e responsabilidade de todos.

\footnotetext{
${ }^{15}$ Constitución española de 1978, disponível no site:

< http://www.congreso.es/consti/constitucion/indice/index.htm>
} 
Quanto ao artículo 45, 3, da constituição espanhola, há um ponto de convergência com a

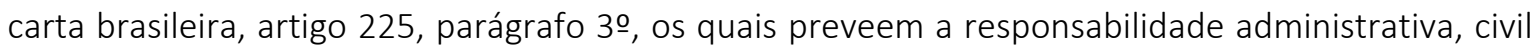
e penal para os atos lesivos à natureza, tanto da pessoa física, como do ente coletivo. No âmbito civil e administrativo, não há excessiva controvérsia, pois é facilmente aceito pelos juristas a possibilidade de sancionar pessoas física e jurídica. Entretanto, quando há a verificação da responsabilidade penal da pessoa jurídica, há certa resistência da doutrina para aceitar essa possibilidade. Como o tema é longo, espinhoso e complexo, necessitaria de um estudo mais pormenorizado; para não ficar com informações sem conclusões, apresenta-se apenas um brevíssimo panorama do tema:

A justiça espanhola aceita e aplica a sanção penal para pessoas jurídicas sem muita resistência, pois o Estado espanhol adotou uma teoria do crime específica para responsabilizar entes morais, não tendo que adaptar situações específicas de pessoas físicas para jurídicas. Quanto ao Brasil, como não há dois arcabouços teóricos diferenciados - um para pessoa física e outro para jurídica - há certa resistência para aceitar a responsabilização desta. Entretanto, a jurisprudência brasileira fez adaptações - muito criticadas pelos juristas - para sancionar entes coletivos.

Quanto ao Estado peruano, verifique o teor de sua Constitución Política del Perú - $1993^{16}$ :

"Artículo $2^{\circ}$ - Toda persona tiene derecho: 22. A la paz, a la tranquilidad, al disfrute del tiempo libre y al descanso, así como a gozar de un ambiente equilibrado y adecuado al desarrollo de su vida.

Artículo $66^{\circ}$.- Los recursos naturales, renovables y no renovables, son patrimonio de la Nación. El Estado es soberano en su aprovechamiento. Por ley orgánica se fijan las condiciones de su utilización y de su otorgamiento a particulares. La concesión otorga a su titular un derecho real, sujeto a dicha norma legal.

Artículo $67^{\circ}$.- El Estado determina la política nacional del ambiente. Promueve el uso sostenible de sus recursos naturales.

Artículo $68^{\circ}$.- El Estado está obligado a promover la conservación de la diversidad biológica y de las áreas naturales protegidas.

Artículo $69^{\circ}$.- El Estado promueve el desarrollo sostenible de la Amazonía con una legislación adecuada." (grifos do autor).

Referente ao meio ambiente, a constituição peruana apresenta o bem jurídico como objeto de proteção específica, como direito a ser desfrutado por todas as pessoas - não fazendo qualquer diferenciação se física ou jurídica - e dever do Estado de preservação do mesmo. Comparando-a com as constituições ora analisadas, verifica a ausência de disposição específica integrando a responsabilidade de tutela do meio ambiente tanto por parte dos poderes públicos

\footnotetext{
${ }^{16}$ Constitución Política del Perú - 1993, disponível no site:

<http://www4.congreso.gob.pe/ntley/Imagenes/Constitu/Cons1993.pdf>
} 
como pela sociedade em cooperação. Somente por intermédio da colaboração entre os setores público e privado é que a iniciativa preservacionista será eficiente.

Quanto ao Chile, verifique a Constitución Política de la Republica de Chile - $1981^{17}$ :

Artículo 19.- La Constitución asegura a todas las personas:

8‥- El derecho a vivir en un medio ambiente libre de contaminación. Es deber del Estado velar para que este derecho no sea afectado y tutelar la preservación de la naturaleza.

La ley podrá establecer restricciones específicas al ejercicio de determinados derechos o libertades para proteger el medio ambiente;

Artículo 20.- El que por causa de actos u omisiones arbitrarios o ilegales sufra privación, perturbación o amenaza en el legítimo ejercicio de los derechos y garantías establecidos en el artículo 19, números 1으, 2으, 3ㅇinciso quinto, 4으, $5 \circ, 60,90$ inciso final, $11^{\circ}, 12^{\circ}, 13^{\circ}, 15 \circ, 160$ en lo relativo a la libertad de trabajo y al derecho a su libre elección y libre contratación, y a lo establecido en el inciso cuarto, $19 \circ, 21^{\circ}, 22^{\circ}, 23^{\circ}, 24^{\circ}$, y 25o podrá ocurrir por sí o por cualquiera a su nombre, a la Corte de Apelaciones respectiva, la que adoptará de inmediato las providencias que juzgue necesarias para restablecer el imperio del derecho y asegurar la debida protección del afectado, sin perjuicio de los demás derechos que pueda hacer valer ante la autoridad o los tribunales correspondientes.

Procederá, también, el recurso de protección en el caso del № 8o del artículo 19, cuando el derecho a vivir en un medio ambiente libre de contaminación sea afectado por un acto $u$ omisión ilegal imputable a una autoridad o persona determinada. (grifos do autor)

o Chile possui uma constituição que também apresenta o meio ambiente como objeto de tutela jurídica, mas acarreta o mesmo problema verificado pelo autor: a falta de específico indicativo de necessidade de cooperação do Estado com a sociedade. Os poderes públicos não tem meios adequados e suficientes para, sozinhos, protegerem o meio ambiente. A disposição é muito importante, devendo ser especificada nas constituições por serem os núcleos axiológicos dos ordenamentos jurídicos que irradiam todos os seus efeitos para normas, sendo vinculantes nas interpretações e aplicações de decisões.

\section{ANÁlise CONSTITUCIONAL do MEIO AMBiENTE AO LONGO DA CONSTRUÇÃo dA NECESSIDADE DE PRESERVAÇÃO DO MEIO AMBIENTE NO BRASIL}

Superando a brevíssima análise das constituições estrangeiras, focando na situação brasileira, deve-se verificar alguns dados para uma análise em contexto adequado: o Brasil é o

17 Constitución Política de la Republica de Chile - 1981, disponível no site: < http://www.leychile.cl/Navegar?idNorma=242302> 
quinto país em extensão territorial ${ }^{18}$, sendo habitado por quase duzentos milhões de habitantes ${ }^{19}$, com 8,8\% de área verde preservada ${ }^{20}$. Esta região de preservação abrange grande biodiversidade e a floresta amazônica - equivocadamente considerada como o "pulmão do mundo" 21.

Apesar do elevado grau de importância do meio ambiente, este ainda não possui significativa proteção jurídica, não tendo o Brasil consolidado plenamente um sistema jurídico de tutela ambiental. Conforme indica Benjamin: "Visto sob todos os ângulos de sua estrutura econômico, cultural e jurídico -, o Brasil ainda dá os primeiros passos na busca da compatibilização entre crescimento econômico e proteção do meio ambiente. [...]"22.

Nos últimos quinhentos anos da História brasileira, a natureza era vista como um obstáculo para o progresso. Este período foi marcado por dois elementos: ferro e fogo. O primeiro indica a utilização do machado e do trator (com a mecanização) como instrumentos essenciais para o desenvolvimento econômico brasileiro. Não menos importante, o outro elemento é a chama, representando a utilização de queimadas e - recentemente - chaminés para o desenvolvimento econômico ${ }^{23}$.

De acordo com essa visão, a mata deveria ser derrubada para criar espaços produtivos, com implantação da agricultura e da pecuária. A título ilustrativo desta forma de pensamento,

18 INSTITUTO BRASILEIRO DE GEOGRAFIA E ESTATíSTICA. Resolução da Presidência do IBGE $n^{\circ}$ 5, de 10 de outubro de 2002 . Diário Oficial da União, Brasília, seção 1, n. 198, p. 48-65, 11 out. 2002. Disponível em:<http://www.ibge.gov.br/home/geociencias/areaterritorial/resolucao.shtm>. Acesso em: 02 jun. 2016.

19 "Os primeiros resultados definitivos, divulgados em novembro de 2010, apontaram uma população formada por 190.732.694 pessoas" (INSTITUTO BRASILEIRO DE GEOGRAFIA E ESTATÍSTICA . Censo 2010. Brasília, IBGE, 2011. Disponível em: <http://www.ibge.gov.br/home/estatistica/populacao/censo2010/default.shtm>. Acesso em: 05 set. 2012.)

20 JUNIOR, Cirilo. Brasil dobra áreas de preservação: total é de 8,8\% do território. Terra, Rio de Janeiro, 18 jun. 2012. Disponível em: <http://invertia.terra.com.br/sustentabilidade/rio20/noticias/0,,Ol5842996El20323,00-Brasil+dobra+areas+de+preservacao+total+e+de+do+territorio.html>. Acesso em: 10 set. 2012.

21 "Muitas vezes já ouvimos falar que a Amazônia é o pulmão do mundo, passando a idéia de que esta floresta teria um importante papel no fornecimento de oxigênio ao planeta. Neste sentido, o simples fato de atribuir à Amazônia o termo "pulmão do mundo" já pode ser considerado um equívoco, pois um pulmão apenas consome, e não produz oxigênio. Além disso, em uma floresta tropical como a Amazônia, o saldo entre o que ela produz de oxigênio e o que consome é praticamente neutro. Durante o dia, a vegetação da floresta libera oxigênio e absorve gás carbônico através da fotossíntese, processo que se inverte durante a noite, quando ocorre a respiração florestal, com a absorção de oxigênio e a liberação de gás carbônico. Porém, essa conta (se haverá mais produção do que absorção de $\mathrm{CO} 2$ ou O2) nem sempre é perfeita e o resultado está associado a outros processos, como as queimadas e o reflorestamento ou expansão da área florestada." (GLOBO AMAZÔNIA. Amazônia, pulmão do mundo? Blog do Green Peace, 27 de set. de 2008. Disponível em: <http://g1.globo.com/platb/natureza-greenpeace/2008/09/27/amazonia-pulmao-domundo/>. Acesso em: 31 out. 2012.).

22 BENJAMIN, Antônio V. Herman. Manual Prático da Promotoria de Justiça do Meio ambiente: volume 1: caderno de direito constitucional. São Paulo: Imprensa Oficial do Ministério Público do Estado de São Paulo, 2005. p. 9.

${ }^{23} \mathrm{lbid}$, p. 9-10. 
cumpre mencionar que, no início do século vinte, havia uma "má fama" do pantanal, devido ao fato de que os cidadãos acreditavam que a vasta floresta, robusta e intransponível pelo homem era um percalço a ser superado pelos brasileiros. Existia a ideia de necessidade de urbanização das áreas inabitadas para obter a prosperidade ${ }^{24}{ }_{-2}$.

Vale ressaltar trecho de periódico brasileiro, do início do referido século, no qual é retratada aquela visão do Brasil em relação ao pantanal e, consequentemente, à natureza:

Aí vimos irmanados pela noção do cumprimento do dever, engenheiros e operários que com uma tenacidade e dedicação digna dos mais merecidos louvores, conquistando com sacrifícios inauditos, não poupando esforços, e até esgotando as suas melhores energias, pretendem remover o obstáculo oposto pelo injustamente mal afamado pantanal, demonstrando aos cépticos a exequibilidade e praticabilidade oportuna do traçado que exigindo menos distância total e melhores probabilidades de remuneração do capital empregado, alia também ótimas qualidades estratégicas. ${ }^{26}$

O processo histórico de construção da consciência de preservação ambiental brasileira demorou (por volta de) quinhentos anos. Mesmo assim, ainda não se pode dizer que há uma consolidação da mesma ${ }^{27}$, embora a atual legislação já confira certo grau significativo de proteção ao meio ambiente.

O meio ambiente obteve proteção específica somente com o advento da Constituição Federal de $1988^{28}$, como fruto da evolução histórica da consciência ambiental. O desenvolvimento da necessidade de preservação deste bem jurídico, no âmbito nacional, pode ser verificado com a análise das legislações ambientais brasileiras, pois a norma é (ou deveria ser) congruente com as transformações sociais.

O Brasil apresentou uma lenta evolução legislativa protecionista ambiental ao longo dos últimos quinhentos anos. Conforme dito no tópico anterior, isso se deve à demora na mudança de

${ }^{24}$ SOUZA, João Carlos de. O progresso contra a natureza: vapor, fios e trilhos em Corumbá (1904/1919). Projeto História, v. 23, p. 217-241, 2001. Disponível em:

<http://revistas.pucsp.br/index.php/revph/article/viewFile/10719/7951>. Acesso em: 02 jun. 2016.

25 “Juscelino Kubitschek de Oliveira (1902-1976), 16o presidente da República (1956-1961), considerava que a natureza --matas, florestas e rios-- impedia o progresso e o desenvolvimento econômico. Conta-se que, em uma conversa com engenheiro Bernardo Saião, disse: "vamos arrombar essa selva.".

Esse pensamento, banido pelo ideal politicamente correto do século 21, era comum no período. Problemas como poluição e trânsito ainda não eram debatidos no Brasil, mesmo porque, foi o governo de JK que acelerou a implantação da indústria automobilística no país." (LIVRARIA DA FOLHA. JK achava que floresta era obstáculo ao progresso: conheça a história. Folha de São Paulo, 12 de set. de 2010. Disponível em: <http://www1.folha.uol.com.br/folha/livrariadafolha/797115-jk-achava-que-floresta-era-obstaculo-aoprogresso-conheca-a-historia.shtml>. Acesso em: 20 out. 2012.)

${ }^{26}$ Loc. cit.

${ }^{27}$ BENJAMIN, Antônio V. Herman. Op. cit., p. 9-10.

${ }^{28}$ MILARÉ, Édis. Direito do ambiente: doutrina, prática, jurisprudência, glossário. São Paulo: Revista dos Tribunais, 2000. p. 211. 
concepção do meio ambiente como obstáculo desenvolvimentista para a atual verificação da natureza como fundamental à vida do homem.

A evolução das leis protecionistas pode ser dividida em três etapas: período da exploração desregrada; legislação fragmentária; fase holística ${ }^{29}$. Estas não representam somente a produção normativa em si, mas também a paulatina mudança de concepção da natureza em relação ao desenvolvimento econômico.

Faria ${ }^{30}$ critica as terminologias usadas para determinar as três fases de evolução legislativa ambiental, indicadas por Benjamin. Em seu dizer, tais etapas seriam mais adequadamente denominadas da seguinte forma: fases fragmentária, setorial e holística. A primeira deve ser assim chamada porque já existe legislação ambiental (de forma setorial) regulamentando as práticas nocivas ao meio ambiente. Quanto à segunda, ao invés de ser período fragmentário, é mais correto dizer ser setorial, pois existiram normas regulamentadoras da natureza divididas em setores de interesses econômicos ${ }^{31}$.

A fase da exploração desregrada compreende o período do descobrimento do Brasil (1500) até a chegada da Família Real ao Brasil (1808) ${ }^{32}$. É assim denominada porque, à época, não existiam leis voltadas à proteção do meio ambiente. Todas as normas tinham a preocupação com a economia da Coroa Portuguesa.

No período do descobrimento do Brasil, a metrópole portuguesa era regida pelas Ordenações Afonsinas (1446), as quais receberam esta denominação por terem sido concluídas durante o reinado de Dom Afonso IV. Esta legislação foi a primeira vigente no Brasil a fazer alusão ao meio ambiente ${ }^{33}$ por meio de dispositivos curiosos, como a tipificação da conduta de cortar árvores frutíferas, que era prevista como crime de injúria ao rei ${ }^{34}$.

Em 1521, passou a vigorar em Portugal e, consequentemente, no Brasil as Ordenações Manuelinas, cujo nome deriva do fato de terem sido criadas no período do reinado de Dom

\footnotetext{
${ }^{29}$ BENJAMIN, Antonio Herman de Vasconcellos. Introdução ao direito ambiental brasileiro: manual prático da promotoria de justiça do meio ambiente e legislação ambiental. 2. ed. São Paulo: IMESC, 1999. p. 22-24.

${ }^{30}$ FARIA, Talden Queiroz. Evolução histórica da legislação ambiental. Revista Âmbito Jurídico, Rio Grande, n. 39, $2007 . \quad$ Disponível em: <http://www.ambitojuridico.com.br/site/index.php?n_link=revista_artigos_leitura\&artigo_id=3845>. Acesso em: 01 nov. 2012.

${ }^{31}$ No presente trabalho serão utilizados os termos propostos por Antônio Herman Benjamin por serem mais difundidos e conhecidos.

32 BENJAMIN, Antônio Herman V. Op. cit., p. 22-24.

${ }^{33}$ FARIA, Talden Queiroz. Op. cit..

${ }^{34}$ DOS ALMUXARIFES, que prendem os mesteriaaes porpor nom hirem aas obras d'elrey. Das forças novas, que som demandadas do anno e dia. In: Ordenações Afonsinas: livro V. Disponível em: <http://www.ci.uc.pt/ihti/proj/afonsinas/15pg276.htm>. Acesso em: 02 jun. 2016.
} 
Manuel I. Em seu livro V, título LXXXIII, havia a proibição da caça de perdizes, lebres e coelhos com instrumentos que pudessem denotar crueldade. O título " $\mathrm{C}$ " manteve a previsão da conduta criminosa de cortar de árvores frutíferas ${ }^{35}$, além de proibir a comercialização de colmeias sem a preservação das abelhas ${ }^{36}$.

Em 1603, com o domínio espanhol, foram aprovadas as Ordenações Filipinas ${ }^{37}$, assim intituladas em razão de terem sido elaboradas na época do reinado de Dom Filipe I. A legislação disciplinou a matéria ambiental no Livro I, título LVIII; livro II, título LIX; livro IV, título XXXIII; e livro $V$, títulos LXXV e LXXVIII ${ }^{38}$. Havia dispositivos que vedavam a conduta de jogar poluentes nas águas criando o risco de causar a mortandade dos peixes e suas criações ou promovessem a poluição dos rios e lagoas ${ }^{39}$. O corte de árvores frutíferas continuou a ser previsto como crime, no Livro V, Título LXXV: haveria a imposição de uma pena corporal de açoite e degredo à África por quatro anos, se o dano fosse pequeno; caso fosse de grande monta, a pena seria de desterro e eterna ${ }^{40}$.

Em 1605, foi criado o regimento do Pau-Brasil, considerado a primeira medida protetiva ambiental a vigorar no Brasil| ${ }^{41}$. A criação deste documento deveu-se ao fato de ter existido não uma exploração, e sim uma verdadeira devastação da madeira desta árvore. Para ilustrar esta situação, cumpre mencionar que em 1546, Duarte Coelho - donatário da capitania de Pernambuco - dirigiu uma carta expondo ao $r \mathrm{ei}^{42} \mathrm{o}$ problema do tráfico da madeira, da impossibilidade de controlar este ilícito e da existência de total desordem por parte dos índios e dos exploradores ${ }^{43}$.

\footnotetext{
${ }^{35}$ A tipificação do corte de árvores frutíferas passou a ser punida com o degrado para o Brasil quando a árvore abatida tivesse valor superior a trinta cruzados. (FARIA, Talden Queiroz. Evolução histórica da legislação ambiental. Revista Âmbito Jurídico, Rio Grande, n. 39, 2007. Disponível em: <http://www.ambitojuridico.com.br/site/index.php?n_link=revista_artigos_leitura\&artigo_id=3845>. Acesso em: 01 nov. 2012).

${ }^{36}$ MEIRA, José de Castro. Direito Ambiental, Informativo Jurídico da Biblioteca Ministro Oscar Saraiva, v. 19, n. 1, jan./jun. 2008, p. 11.

${ }^{37}$ Ordenações Filipinas disponíveis no site: http://www1.ci.uc.pt/ihti/proj/filipinas//1ind.htm

${ }^{38}$ MEIRA, José de Castro. Direito Ambiental, Informativo Jurídico da Biblioteca Ministro Oscar Saraiva, v. 19, n. 1, jan./jun. 2008, p. 11.

${ }^{39}$ FARIA, Talden Queiroz. Evolução histórica da legislação ambiental. Revista Âmbito Jurídico, Rio Grande, n. 39, $2007 . \quad$ Disponível em: <http://www.ambitojuridico.com.br/site/index.php?n_link=revista_artigos_leitura\&artigo_id=3845>. Acesso em: 01 nov. 2012.

${ }^{40}$ MORAES, Alexandre de. Direito constitucional. 8. ed. São Paulo: Atlas, 2000. p. 646.

${ }^{41}$ BRASIL. Superior Tribunal de Justiça, Coordenadoria de Editoria e Imprensa. Linha do tempo: um breve resumo da evolução da legislação ambiental no Brasil. 4 jun. 2010. Disponível em: $<$ http://www.stj.jus.br/portal_stj/publicacao/engine.wsp?tmp.area=398\&tmp.texto=97547>. Acesso em: 14 fev. 2013.

${ }^{42}$ Trecho da carta de Duarte Coelho dirigida ao rei de Portugal: "Já tenho escrito a V.A. e Ihe fiz saber por outras que escritas Ihe tenho que uma das cousas que mais danifica ao bem e aumento de suas terras é fazer-se brasil [...] que está longe pelo sertão [...] Esse que eu tenho mandado estes anos passados para V. A. [...] faz-se tudo por sua ordem e muito devagar conforme a condição dos índios [...], mas a esses a quem V. A. fez mercê de brasil [...] importunam tanto os índios e prometem-lhe tantas cousas fora de ordem que me
} 
O regimento do Pau-Brasil determinava a necessidade de haver uma ordem do ProvedorMor da fazenda para o corte da referida madeira, prevendo, ainda, requisitos para que fosse concedida tal permissão, a saber: ser o explorador pessoa idônea; respeito ao destino indicado no documento autorizador; extração dentro dos limites previstos na legislação. O descumprimento destas condições acarretaria desde a pena de multa, até a de morte, além da perda da fazenda ${ }^{44}$.

Em razão das práticas abusivas praticadas pelos roceiros, particulares e madeireiros ${ }^{45}{ }^{46}$, em 1797, foi elaborado o primeiro documento específico com conteúdo ambiental: uma carta régia de 11 de julho de 1799, na qual se afirmava a necessidade de proteção dos rios, suas nascentes e encostas ${ }^{47}$. De acordo com este documento, estes terrenos passaram a serem propriedades da Coroa ${ }^{48}$, além de ter havido a criação do Regimento dos Cortes de Madeira para o Brasil, o qual regulamentou o trabalho com o corte da madeira.

têm a terra toda em desordem da ordem a que a tenho posto [...]" (COELHO, Duarte. Carta de Duarte Coelho ao Rei em 20.12.1546. In: SOUZA, Bernardino José de. O pau-brasil na história nacional. São Paulo: Companhia Editora nacional, 1939).

${ }^{43}$ SIQUEIRA, Maria Isabel de. Considerações sobre ordem em colônias: as legislações na exploração do paubrasil. CLIO - Revista de Pesquisa Histórica, v. 29, n. 1, 2011. Disponível em: <http://www.revista.ufpe.br/revistaclio/index.php/revista/article/viewFile/168/112>. Acesso em: 23 jan. 2013.

${ }^{44}$ BRAVO, André Luiz Morais Zuzarte; SIQUEIRA, Maria Isabel de. As ordens metropolitanas e a realidade colonial: os caminhos e descaminhos do pau-brasil na sociedade carioca do período filipino. In ENCONTRO REGIONAL DA ANPUH-RIO, 14., 2010, Rio de Janeiro. Anais... Disponível em: <http://www.encontro2010.rj.anpuh.org/resources/anais/8/1276722986_ARQUIVO_PuPublicacaoANP-

AndreLuizMorais.pdf>. Acesso em: 25 jan. 2013.

45 PEREIRA, Rodrigo Osório. O papel dos "ilustrados" da comarca de ilhéus na regulamentação dos reais cortes de madeira: 1784-1799. In: ENCONTRO ESTADUAL DE HISTÓRIA, 3., 2006, Caetité. Anais... Caetité: UNEB, 2006. Disponível em: <http://www.uesb.br/anpuhba/artigos/anpuh_III/rodrigo_osorio.pdf>. Acesso em: 21 jan. 2013.

46 "Seja nas funções de inspetor dos reais cortes e juiz conservador das matas ou mesmo assumindo outros cargos não necessariamente ligados à questão da madeira, vários intelectuais baianos manifestaram em seus discursos uma crítica contra os abusos praticados pelos roceiros, particulares e madeireiros frente as florestas ou mesmo quanto à má administração dos cortes. São inúmeros os documentos onde encontramos uma crítica ambiental, envolvendo denúncias e forçando o Estado a adotar uma política imediata de solução. Vozes em favor da natureza ecoaram já em fins do século XVIII [...]" (PEREIRA, Rodrigo Osório. O papel dos "ilustrados" da comarca de ilhéus na regulamentação dos reais cortes de madeira: 1784-1799. In: ENCONTRO ESTADUAL DE HISTÓRIA, 3., 2006, Caetité. Anais... Caetité: UNEB, 2006. Disponível em: $<$ http://www.uesb.br/anpuhba/artigos/anpuh_III/rodrigo_osorio.pdf>. Acesso em: 21 jan. 2013.).

47 "todas as matas e arvoredos à borda da costa, ou de rios que desemboquem imediatamente no mar, e por onde em jangadas se possam conduzir as madeiras cortadas até a praia" (Carta Régia de 13 de Março de 1797, PEREIRA, Rodrigo Osório. O papel dos "ilustrados" da comarca de ilhéus na regulamentação dos reais cortes de madeira: 1784-1799. In: ENCONTRO ESTADUAL DE HISTÓRIA, 3., 2006, Caetité. Anais... Caetité: UNEB, 2006. Disponível em: <http://www.uesb.br/anpuhba/artigos/anpuh_III/rodrigo_osorio.pdf>. Acesso em: 21 jan. 2013.).

${ }^{48}$ BRASIL. Superior Tribunal de Justiça, Coordenadoria de Editoria e Imprensa. Linha do tempo: um breve resumo da evolução da legislação ambiental no Brasil. 4 jun. 2010. Disponível em: 
Em 1802, por recomendação de José Bonifácio, foram baixadas as primeiras instruções para reflorestar a costa brasileira ${ }^{49}$. Encerrava-se, portanto, o período da exploração desregrada, dando início à fase fragmentária da história legislativa ambiental brasileira.

A fase fragmentária compreende o período da vinda da Família Real ao Brasil (1808) até a criação da Lei da Política Nacional do Meio Ambiente (1981) ${ }^{50}$. Nesta etapa, foram criadas leis esparsas protetoras do meio ambiente, que, contudo, não constituíram um efetivo sistema de proteção, mas tão somente âmbitos de tutelas setorizadas.

Em 1808, surgiu a primeira unidade de conservação no Brasil: criado pelo príncipe regente Dom João VI com o objetivo de aclimatar especiarias vindas das Índias Orientais, o Jardim Botânico representou um estímulo à preservação ambiental e à realização de estudos científicos na área botânica ${ }^{51}$. Ainda com relação à etapa fragmentária, em 1809, Dom João VI expediu a Ordem de 09 de abril de 1809, por meio da qual concedia a liberdade a escravos que contribuíssem com a captura de contrabandistas de pau-brasil. Oito anos depois, o monarca elaborou o Decreto de 3 de agosto de 1817, proibindo a derrubada de árvores nas margens do rio Carioca (Rio de Janeiro) ${ }^{52}$.

Em 25 de março de 1824 foi outorgada a Constituição Política do Império do Brasil ${ }^{53}$, a qual, no que se refere ao meio ambiente, inovou ao estabelecer a proibição de trabalho, cultura, indústria ou comércio que se opusessem à segurança e saúde dos cidadãos - art. 179, XXIV54.

O Código Criminal de 1830 trouxe a previsão dos crimes de corte ilegal de árvores ${ }^{55}$ e dano ao patrimônio cultural ${ }^{56}{ }_{-5}^{57}$. O primeiro foi inovador por ter retirada a conduta de cortar árvores

$<$ http://www.stj.jus.br/portal_stj/publicacao/engine.wsp?tmp.area=398\&tmp.texto=97547>. Acesso em: 14 fev. 2013.

49 BURSZTYN, Marcel; PERSEGONHA, Marcelo. A grande transformação ambiental: uma cronologia da dialética homem-natureza. Rio de Janeiro: Garamond LTDA, 2008. p. 45.

${ }^{50}$ BENJAMIN, Antônio Herman V.. Op. cit., p. 22-24.

51 INSTITUTO DE PESQUISAS JARDIM BOTÂNICO DO RIO DE JANEIRO. Histórico. Disponível em: $<$ http://www.jbrj.gov.br/historic/index.htm>. Acesso em: 02 jun. 2016.

${ }^{52}$ MEIRA, José de Castro. Direito ambiental. Informativo Jurídico da Biblioteca Ministro Oscar Saraiva, v. 19, n. 1, jan./jun., $\quad$ p. 11-23, $2008 . \quad$ Disponível em: $<$ http://www.stj.jus.br/publicacaoseriada/index.php/informativo/article/view/50/54>. Acesso em: 12 jan. 2013. p. 12.

${ }^{53}$ BRASIL. Constituição (1824). Constituição Política do Império do Brasil. Rio de Janeiro, 1824. Disponível em: <http://bd.camara.gov.br/bd/handle/bdcamara/1737>. Acesso em: 06 set. 2012.

${ }^{54}$ Maiores detalhes acerca da proteção constitucional ambiental, no próximo tópico do presente trabalho.

${ }^{55}$ Há vasta doutrina indicando ser o art. 257 do Código Criminal de 1830 a prever o delito de corte ilegal de árvore. Contudo, o dispositivo indica ser o crime de furto: "Art. 257 - tirar a cousa alheia contra a vontade do seu dono. Penas - de prisão com trabalho por dous mezes a quatro ânuos, e de multa de cinco a vinte por cento do valor furtado" (BRASIL. Código Criminal (1830). Código Criminal do Império do Brasil. Rio de Janeiro, 1830. Disponível em: <http://www2.senado.gov.br/bdsf/bitstream/id/221763/1/000750858.pdf>. Acesso em: 06 set. 2012.) 
como parte do tipo de injúria (ao rei). O segundo foi importante por ter dado status de bem público o meio ambiente cultural.

Vinte anos depois, foi criada a lei 601/1850, mais conhecida como Lei de Terras. Esta foi a primeira iniciativa governamental objetivando a regulamentação das propriedades privadas no Brasil $^{58}$. Esta legislação criada por Dom Pedro II proibia a exploração florestal nas terras descobertas. Contudo, a norma não foi respeitada. Houve o contínuo desmatamento para o desenvolvimento da indústria cafeeira ${ }^{59}$.

Em 24 de fevereiro de 1891, foi promulgada a primeira Constituição da República dos Estados Unidos do Brasil ${ }^{60}$. Em relação ao meio ambiente, a Carta conferiu competência privativa do Congresso Nacional para legislar sobre terras e minas de propriedade da União - art. 34, ํo 29 61.

Outras leis foram criadas com pequeno grau de importância e restrita proteção ao meio ambiente. Entre estas, há o Decreto 8.843 de 1891, responsável pela criação da reserva florestal do Acre - que, até a presente data, não foi implantada. Além disso, também foi criado o primeiro parque estadual em São Paulo: Parque da Cidade, em $1896^{62}$.

\footnotetext{
56 “Destruição ou damnificação de construcções, monumentos e bens públicos. Art. 178 do Código Criminal de 1830 - "Destruir, abater, mutilar ou damnificar monumentos, edificios, bens públicos ou quaisquer outros objectos destinados á utilidade, decoração ou recreio público. Penas - de prisão com trabalho por dous mezes a quatro annos, e de multa de cinco a vinte por cento do damno causado" (BRASIL. Código Criminal (1830). Código Criminal do Império do Brasil. Rio de Janeiro, 1830. Disponível em: <http://www2.senado.gov.br/bdsf/bitstream/id/221763/1/000750858.pdf>. Acesso em: 06 set. 2012.)

57 BRASIL. Código Criminal (1830). Código Criminal do Império do Brasil. Rio de Janeiro, 1830. Disponível em: <http://www2.senado.gov.br/bdsf/bitstream/id/221763/1/000750858.pdf>. Acesso em: 06 set. 2012.

${ }^{58}$ Lei n ${ }^{\circ}$ 601, de 18 de setembro de 1850: "Dispõe sobre as terras devolutas no Império, e acerca das que são possuídas por titulo de sesmaria sem preenchimento das condições legais. bem como por simples titulo de posse mansa e pacifica; e determina que, medidas e demarcadas as primeiras, sejam elas cedidas a titulo oneroso, assim para empresas particulares, como para o estabelecimento de colonias de nacionaes e de extrangeiros, autorizado o Governo a promover a colonisação extrangeira na forma que se declara". (BRASIL. Lei $n^{\circ} 601 / 50$, de 18 de setembro de 1850. Dispõe sobre as terras devolutas do Império. Conjunto de Leis Brasileiras, Rio de Janeiro, v. 1, p. 307, 18 set. 1850. Disponível em: <http://www.planalto.gov.br/ccivil_03/Leis/L0601-1850.htm>. Acesso em: 20 dez. 2012.).

${ }^{59}$ BRASIL. Ministério do Meio Ambiente. Histórico brasileiro. Política de Educação Ambiental. Disponível em: $<$ http://www.mma.gov.br/educacao-ambiental/politica-de-educacao-ambiental/historico-brasileiro>. Acesso em: 09 jan. 2013.

${ }^{60}$ BRASIL. Constituição (1891). Constituição da República dos Estados Unidos do Brasil. Rio de Janeiro, 1891. Disponível em: <http://www.planalto.gov.br/ccivil_03/constituicao/constitui\%C3\%A7ao91.htm>. Acesso em: 06 set. 2012.

${ }^{61}$ Maiores detalhes acerca da proteção constitucional ambiental, no próximo tópico do presente trabalho.

62 Loc. cit.
} 
Em 1916, entrou em vigor o Código Civil brasileiro ${ }^{63}$. Esta legislação apresentou avanços consideráveis acerca da regulamentação e proteção do meio ambiente, com destaque para os seguintes artigos:

Art. 554. O proprietário, ou inquilino de um prédio tem o direito de impedir que o mão [sic] uso da propriedade vizinha possa prejudicar a segurança, o sonego e a saúde dos que o habitam.

Art. 584. São proibidas construções capazes de poluir, ou inutilizar para o uso ordinário a água de poço ou fonte alheia, a elas preexistente.

Apesar de a lei 3071/1916 possuir um viés patrimonialista, este último dispositivo foi mais inovador ao proteger o meio ambiente de forma explícita. Quanto ao art. 554 do Código Civil de 1916, Silva ${ }^{64}$ ressalta sua importância ao afirmar que era necessário "para fundamentar a ação cominatória visando a impedir a contaminação do meio ambiente por parte de indústrias". Iniciava-se, assim, a disseminação de uma visão voltada para a função socioambiental da propriedade ${ }^{65}$.

O Regulamento da Saúde Pública - Dec. 16.300/23 - previu a “[...] possibilidade de impedir que as indústrias prejudicassem a saúde dos moradores de sua vizinhança, possibilitando o

${ }^{63}$ BRASIL. Lei no 3.071/16, de 1 de janeiro de 1916. Código Civil Dos Estados Unidos Do Brasil. Coleção de Leis do Brasil, Brasília, 1 jan. 1916. Disponível em: <http://www.planalto.gov.br/ccivil_03/leis/L3071.htm>. Acesso em: 02 jun. 2016.

${ }^{64}$ SILVA, José Afonso da Direito ambiental constitucional. 5. ed. São Paulo: Malheiros, 2004. p. 35.

${ }^{65}$ Atualmente, a função socioambiental da propriedade é prevista na Constituição da República Federativa do Brasil de 1988, art. 186 e no Código Civil Brasileiro, art. 1.228, §1ㅇ:

Constituição da República Federativa do Brasil de 1988, art. 186: "A função social é cumprida quando a propriedade rural atende, simultaneamente, segundo critérios e graus de exigência estabelecidos em lei, aos seguintes requisitos:

I- aproveitamento racional e adequado;

II - utilização adequada dos recursos naturais disponíveis e preservação do meio ambiente;

III - observância das disposições que regulam as relações de trabalho;

IV - exploração que favoreça o bem-estar dos proprietários e dos trabalhadores".

CC/02, art. 1.228, § 10: "O direito de propriedade deve ser exercido em consonância com as suas finalidades econômicas e sociais e de modo que sejam preservados, de conformidade com o estabelecido em lei especial, a flora, a fauna, as belezas naturais, o equilíbrio ecológico e o patrimônio histórico e artístico, bem como evitada a poluição do ar e das águas".

"[...] o conceito de propriedade contemporânea compreende em seu conteúdo e alcance, além do tradicional direito de uso, gozo e disposição dos bens por parte de seus titulares (CC, art. 524), com as progressivas limitações (CC., arts. 554 a 588, 591), a obrigatoriedade do atendimento de sua função social, cujo conceito é inseparável do requisito obrigatório do uso racional da propriedade e dos recursos ambientais que lhe são integrantes. O proprietário (pessoa física ou jurídica, esta de direito público ou privado), como membro integrante da comunidade, sujeita-se a obrigações crescentes que, ultrapassando os limites do direito de vizinhança, no âmbito do direito privado, abrange, o campo dos direitos de coletividade, visando o bem-estar geral, no âmbito do direito público" (CUSTÓDIO, Helita Barreira. Questão constitucional: propriedade, ordem econômica e dano ambiental. Competência legislativa concorrente. In: BENJAMIN, Antonio Herman V. Dano ambiental: prevenção, reparação e repressão. São Paulo: Revista dos Tribunais, 1993. P. 118. (Biblioteca de direito ambiental).). 
afastamento das indústrias nocivas ou incômodas" ${ }^{66}$. Na década de trinta, o legislador brasileiro passou a criar leis específicas de proteção ao meio ambiente, destacam-se o Código Florestal (Dec. 23.793/34) ${ }^{67}$, o Código das Águas (Dec. 24.643/34), a Lei de Proteção da Fauna (Dec. 24.645/34) e a Lei de Organização e Proteção ao Patrimônio histórico e Artístico Nacional (Dec. 25/37).

Na mesma época, foi promulgada a Constituição da República dos Estados Unidos do Brasil - de 16 de julho de $1934{ }^{68}$, que fixou a competência concorrente da União e dos Estados para proteger as belezas naturais e os monumentos históricos ou artísticos, podendo impedir a evasão de obras de arte - arts. 10, III; 148. Além disso, determinou ser de competência da União legislar sobre bens do domínio federal, riquezas do subsolo, mineração, metalurgia, águas, energia hidrelétrica, florestas, caça e pesca - art. 5으 XIX, j.

Cerca de três anos depois, foi outorgada a Constituição dos Estados Unidos do Brasil - de 10 de novembro de $1937^{69}$. Os artigos 134; 16, XIV; 18, a eram responsáveis pela tutela do meio ambiente, fixando as competências para legislar acerca do tema, a saber:

Art. 134 - Os monumentos históricos, artísticos e naturais, assim como as paisagens ou os locais particularmente dotados pela natureza, gozam da proteção e dos cuidados especiais da Nação, dos Estados e dos Municípios. Os atentados contra eles cometidos serão equiparados aos cometidos contra o patrimônio nacional.

Art. 16 - Compete privativamente à União o poder de legislar sobre as seguintes matérias: XIV - os bens do domínio federal, minas, metalurgia, energia hidráulica, águas, florestas, caça e pesca e sua exploração.

Art. 18 - Independentemente de autorização, os Estados podem legislar, no caso de haver lei federal sobre a matéria, para suprir-Ihes as deficiências ou atender às peculiaridades locais, desde que não dispensem ou diminuam es exigências [sic] da lei federal, ou, em não havendo lei federal e até que esta regule, sobre os seguintes assuntos: a) riquezas do subsolo, mineração, metalurgia, águas, energia hidrelétrica, florestas, caça e pesca e sua exploração.

Em 18 de setembro de 1946, foi promulgada a Constituição dos Estados Unidos do Brasil ${ }^{70}$. Nos termos do art. 175: "As obras, monumentos e documentos de valor histórico e artístico, bem

66 SILVA, Thomas de Carvalho. O meio ambiente na constituição federal de 1988. Revista Atualidades Jurídicas, $\quad$ n. $8, \quad$ nov./dez., $\quad$ p. 170-181, 2009. Disponível em: <http://www.oab.org.br/editora/revista/revista_08/anexos/o_meio_ambiente_na_constitconst_federal.pdf> . Acesso em: 05 jan. 2013.

67 Revogado atualmente pela lei federal 4771/65.

68 BRASIL. Constituição (1934). Constituição da República dos Estados Unidos do Brasil. Rio de Janeiro, 1934. Disponível em: <http://www.planalto.gov.br/ccivil_03/constituicao/constitui\%C3\%A7ao34.htm>. Acesso em: 06 set. 2012.

69 BRASIL. Constituição (1937). Constituição da República dos Estados Unidos do Brasil . Rio de Janeiro, 1937. Disponível em: <http://www.planalto.gov.br/ccivil_03/constituicao/constitui\%C3\%A7ao34.htm>. Acesso em: 06 set. 2012. 
como os monumentos naturais, as paisagens e os locais dotados de particular beleza ficam sob a proteção do Poder Público.". Tal como a Carta anterior, houve a manutenção da competência da União para legislar sobre as riquezas do subsolo, mineração, metalurgia, águas, energia elétrica, floresta, caça e pesca, no texto do art. 5o, XV, I.

Na década de sessenta, o legislador continuou a criar normas regulamentadoras do meio ambiente. Importante mencionar, entre elas, o Estatuto da Terra (Lei 4504/64), a nova lei de Proteção da Fauna (Lei 5197/67), o Código da Caça (Lei 5197/67), o Código da Mineração (Dec. Lei 337/67), decreto regulamentador da Política Nacional do Saneamento Básico (Dec. 248/67) e o decreto para a criação do Conselho Nacional de Controle da poluição Ambiental (Dec. 303/67).

Além das legislações supracitadas, em 24 de janeiro de 1967 foi outorgada uma nova Constituição da República Federativa do Brasil ${ }^{71}$. Quanto ao meio ambiente, a Carta determinou em seu artigo 172 que "O amparo à cultura é dever do Estado. Parágrafo único - Ficam sob a proteção especial do Poder Público os documentos, as obras e os locais de valor histórico ou artístico, os monumentos e as paisagens naturais notáveis, bem como as jazidas arqueológicas.". Quanto à disposição da competência para legislar sobre a natureza, o art. 8o, XVII, $h$ manteve a da União para dispor sobre jazidas, metalurgia, florestas, caça, pesca, minas e outros recursos minerais.

Em 17 de outubro de 1969, foi outorgada a emenda constitucional no. 1/69, a qual modificou profundamente o texto constitucional de $1967^{72}$. Em relação ao meio ambiente, a Carta manteve a forma de disposição acerca da natureza. Houve alteração do artigo 172 da Constituição de 1967 ao inserir o termo "ecológico" no dispositivo: "A lei regulará, mediante prévio levantamento ecológico, o aproveitamento agrícola de terras sujeitas a intempéries e calamidades. O mau uso da terra impedirá o proprietário de receber incentivos e auxílios do Governo" (grifo do autor).

\footnotetext{
70 BRASIL. Constituição (1946). Constituição da República dos Estados Unidos do Brasil . Rio de Janeiro, 1946. Disponível em: <http://www.planalto.gov.br/ccivil_03/constituicao/constitui\%C3\%A7ao46.htm>. Acesso em: 06 set. 2012.

${ }^{71}$ BRASIL. Constituição (1967). Constituição da República dos Estados Unidos do Brasil . Rio de Janeiro, 1967. Disponível em: <http://www.planalto.gov.br/ccivil_03/constituicao/constituicao67.htm>. Acesso em: 06 set. 2012.

72 BRASIL. Constituição (1969). Emenda constitucional no 1, de 17 de outubro de 1969. Edita o novo texto da Constituição Federal de 24 de janeiro de 1967. Diário Oficial da União, Brasília, p. 8865, 20 out. 1969. Disponível em: <http://www.planalto.gov.br/ccivil_03/constituicao/emendas/emc_anterior1988/emc0169.htm>. Acesso em: 06 set. 2012.
} 
Em 1972, a Conferência das Nações Unidas para o Meio Ambiente (Estocolmo/Suécia) contou com ativa participação por parte do Brasil, que se comprometeu a adotar medidas para um desenvolvimento sustentável ${ }^{73}$. Encerrava-se a fase fragmentária da legislação ambiental, iniciando a fase holística.

O marco inicial desta etapa consistiu na criação da Lei da Política Nacional do Meio Ambiente (Lei 6938/81), com o que se convencionou chamar de "(re) orientação de rumo". Esta legislação tratou o meio ambiente como um fim em si mesmo, objeto de tutela integral como sistema ecológico integrado, uma vez que se trata de bem jurídico relevante para a sociedade e com extensa autonomia axiológica. Além deste marco legislativo, destacam-se as leis de ação popular (lei 4717/65) e a de ação civil pública (lei 7347/85) como importantes avanços na proteção da natureza ${ }^{74}$.

Em 5 de outubro de 1988, foi promulgada a Constituição da República Federativa do Brasil de $1988^{75}$. A constituição cidadã foi o primeiro texto constitucional a trazer tutela ao meio ambiente de forma específica e global ${ }^{76}$, tendo previsto em um capítulo específico as regras e princípios que regulamentam este bem jurídico fundamental. Entre os dispositivos constitucionais vigentes, destacam-se: art. 5ㅇ, LXXIII - ação popular como instrumento de tutela ambiental; art. 20, II - XI e parágrafo 1 - bens da União; art. 23, I, II, III, IV, VI, VII, IX e XI - competência administrativa, comum, cumulativa ou paralela, atribuída em relação aos quatro entes federativos; art. 24, VI, VII, VIII e XII - competência legislativa concorrente para dispor sobre o meio ambiente; art. 26, I, II e III - bens dos estados; art. 30, VIII e IX - competência privativa dos municípios para dispor sobre o bem jurídico em comento; art. 91, parágrafo 1ํㅡ. III - atribuição do Conselho Nacional de Defesa; art. 129, III - função institucional do Ministério Público para promoção de inquérito civil e ajuizamento da ação civil pública; art. 170, VI - princípio da ordem econômica; art. 174, parágrafo 3o - organização da atividade garimpeira e cooperativas; art. 176, parágrafo 1ㅇ recursos minerais e potenciais de energia hidráulica; art. 186, II - função social da propriedade

73 SILVA, Thomas de Carvalho. O meio ambiente na constituição federal de 1988. Revista Atualidades Jurídicas, $\quad$ n. $8, \quad$ nov./dez., $\quad$ p. 170-181, 2009. Disponível em: <http://www.oab.org.br/editora/revista/revista_08/anexos/o_meio_ambiente_na_constitconst_federal.pdf> . Acesso em: 05 jan. 2013.

${ }^{74}$ ABRÃO, Bernardina Ferreira Furtado. Desenvolvimento econômico e preservação ambiental: o papel das políticas públicas sustentáveis. In: CONGRESSO INTERNACIONAL DE DIREITO AMBIENTAL, 12., 2008, São Paulo. Mudanças Climáticas, biodiversidade e uso sustentável de energia. v.2. São Paulo: Imprensa Oficial do Estado de São Paulo, 2008. p. 75.

${ }^{75}$ BRASIL. Constituição (1988). Constituição da República Federativa do Brasil. Brasília, DF: Senado, 1988.

76 MILARÉ, Édis. Direito do ambiente: doutrina, prática, jurisprudência, glossário. São Paulo: Revista dos Tribunais, 2000. p. 211. 
rural; art. 200, VIII - meio ambiente do trabalho; art. 216, V - patrimônio cultural brasileiro; art. 220, parágrafo 3ํ, II - comunicação social e proteção ambiental; art. 225 - proteção, de modo específico e global, do meio ambiente; art. 231, parágrafos 1ㅇ e 3o - tutela dos índios, entre outros dispositivos constitucionais.

\section{REFERÊNCIAS}

ABRÃO, Bernardina Ferreira Furtado. Desenvolvimento econômico e preservação ambiental: o papel das políticas públicas sustentáveis. In: CONGRESSO INTERNACIONAL DE DIREITO AMBIENTAL, 12., 2008, São Paulo. Mudanças Climáticas, biodiversidade e uso sustentável de energia. v.2. São Paulo: Imprensa Oficial do Estado de São Paulo, 2008.

BENJAMIN, Antonio Herman de Vasconcellos. Introdução ao direito ambiental brasileiro: manual prático da promotoria de justiça do meio ambiente e legislação ambiental. 2. ed. São Paulo: IMESC, 1999.

Manual Prático da Promotoria de Justiça do Meio ambiente: volume 1: caderno de direito constitucional. São Paulo: Imprensa Oficial do Ministério Público do Estado de São Paulo, 2005.

BOBBIO, Norberto. A era dos direitos. Rio de Janeiro: Campus Elsevier, 1992.

BRASIL. Código Criminal (1830). Código Criminal do Império do Brasil. Rio de Janeiro, 1830. Disponível em: <http://www2.senado.gov.br/bdsf/bitstream/id/221763/1/000750858.pdf>. Acesso em: 06 set. 2012.

Constituição (1824). Constituição Política do Império do Brasil. Rio de Janeiro, 1824. Disponível em: <http://bd.camara.gov.br/bd/handle/bdcamara/1737>. Acesso em: 06 set. 2012.

Constituição (1891). Constituição da República dos Estados Unidos do Brasil. Rio de Janeiro, 1891. Disponível

em: <http://www.planalto.gov.br/ccivil_03/constituicao/constitui\%C3\%A7ao91.htm>. Acesso em: 06 set. 2012. 1934.

Constituição (1934). Constituição da República dos Estados Unidos do Brasil. Rio de Janeiro, <http://www.planalto.gov.br/ccivil_03/constituicao/constitui\%C3\%A7a034.htm>. Acesso em: 06 set. 2012. 1937.

Constituição (1937). Constituição da República dos Estados Unidos do Brasil. Rio de Janeiro, <http://www planalto gov.br/ccivil_03/constituicao/constitui\%C3\%A7a034.htm>. Acesso em: 06 set. 2012. 1946.

Constituição (1946). Constituição da República dos Estados Unidos do Brasil. Rio de Janeiro, <http://www planalto gov.br/ccivil03/constituicao/constitui\%c3\%A7a046.htm>. Acesso em: 06 set. 2012.

Constituição (1967). Constituição da República dos Estados Unidos do Brasil. Rio de Janeiro, 1967. Disponível em: <http://www.planalto.gov.br/ccivil_03/constituicao/constituicao67.htm>. Acesso em: 06 set. 2012. 
Constituição (1969). Emenda constitucional no 1, de 17 de outubro de 1969. Edita o novo texto da Constituição Federal de 24 de janeiro de 1967. Diário Oficial da União, Brasília, p. 8865, 20 out. $1969 . \quad$ Disponível em: <http://www.planalto.gov.br/ccivil_03/constituicao/emendas/emc_anterior1988/emc01-69.htm>. Acesso em: 06 set. 2012.

\section{8.}

Constituição (1988). Constituição da República Federativa do Brasil. Brasília, DF: Senado,

Lei no 3.071/16, de 1 de janeiro de 1916. Código Civil Dos Estados Unidos Do Brasil. Coleção de Leis do Brasil, Brasília, 1 jan. 1916. Disponível em: <http://www.planalto.gov.br/ccivil_03/leis/L3071.htm>. Acesso em: 02 jun. 2016.

Lei $n^{\circ} 601 / 50$, de 18 de setembro de 1850. Dispõe sobre as terras devolutas do Império. Conjunto de Leis Brasileiras, Rio de Janeiro, v. 1, p. 307, 18 set. 1850. Disponível em: <http://www.planalto.gov.br/ccivil_03/Leis/L0601-1850.htm>. Acesso em: 20 dez. 2012.

Ministério do Meio Ambiente. Histórico brasileiro. Política de Educação Ambiental. Disponível em: <http://www.mma.gov.br/educacao-ambiental/politica-de-educacao-ambiental/historicobrasileiro>. Acesso em: 09 jan. 2013.

Superior Tribunal de Justiça, Coordenadoria de Editoria e Imprensa. Linha do tempo: um breve resumo da evolução da legislação ambiental no Brasil. 4 jun. 2010. Disponível em: <http://www.stj.jus.br/portal_stj/publicacao/engine.wsp?tmp.area=398\&tmp.texto=97547>.

Acesso em: 14 fev. 2013.

Superior Tribunal de Justiça, Coordenadoria de Editoria e Imprensa. Linha do tempo: um breve resumo da evolução da legislação ambiental no Brasil. 4 jun. 2010. Disponível em: $<$ http://www.stj.jus.br/portal_stj/publicacao/engine.wsp?tmp.area=398\&tmp.texto=97547>.

Acesso em: 14 fev. 2013.

BRAVO, André Luiz Morais Zuzarte; SIQUEIRA, Maria Isabel de. As ordens metropolitanas e a realidade colonial: os caminhos e descaminhos do pau-brasil na sociedade carioca do período filipino. In ENCONTRO REGIONAL DA ANPUH-RIO, 14., 2010, Rio de Janeiro. Anais.... Disponível em: <http://www.encontro2010.rj.anpuh.org/resources/anais/8/1276722986_ARQUIVO_PuPublicacao ANP-AndreLuizMorais.pdf>. Acesso em: 25 jan. 2013.

BURSZTYN, Marcel; PERSEGONHA, Marcelo. A grande transformação ambiental: uma cronologia da dialética homem-natureza. Rio de Janeiro: Garamond LTDA, 2008.

CASTRO, Carlos Roberto Siqueira. A Constituição aberta e os direitos fundamentais.

COELHO, Duarte. Carta de Duarte Coelho ao Rei em 20.12.1546. In: SOUZA, Bernardino José de. O pau-brasil na história nacional. São Paulo: Companhia Editora nacional, 1939.

CONSTITUCIÓN POLÍTICA DE LA REPUBLICA DE CHILE - 1981, disponível no site: < http://www.leychile.cl/Navegar?idNorma=242302>

CUSTÓDIO, Helita Barreira. Questão constitucional: propriedade, ordem econômica e dano ambiental. Competência legislativa concorrente. In: BENJAMIN, Antonio Herman V. Dano ambiental: prevenção, reparação e repressão. São Paulo: Revista dos Tribunais, 1993. Biblioteca de direito ambiental. 
FARIA, Talden Queiroz. Evolução histórica da legislação ambiental. Revista Âmbito Jurídico, Rio Grande, $\quad$ n. 39, $2007 . \quad$ Disponível em: <http://www.ambitojuridico.com.br/site/index.php?n_link=revista_artigos_leitura\&artigo_id=3845>. Acesso em: 01 nov. 2012.

FARIAS, Paulo José Leite. Competência federativa e proteção ambiental. Porto Alegre: Sérgio Antônio Fabris.

GLOBO AMAZÔNIA. Amazônia, pulmão do mundo? Blog do GreenPeace, 27 de set. de 2008. Disponível em: <http://g1.globo.com/platb/natureza-greenpeace/2008/09/27/amazonia-pulmaodo-mundo/>. Acesso em: 31 out. 2012.

INSTITUTO BRASILEIRO DE GEOGRAFIA E ESTATÍSTICA. Censo 2010. Brasília, IBGE, 2011. Disponível em: <http://www.ibge.gov.br/home/estatistica/populacao/censo2010/default.shtm>. Acesso em: 05 set. 2012.

Resolução da Presidência do IBGE $n^{\circ}$ 5, de 10 de outubro de 2002 . Diário Oficial da União, Brasília, seção 1, n. 198, p. 48-65, 11 out. 2002. Disponível em:<http://www.ibge.gov.br/home/geociencias/areaterritorial/resolucao.shtm>. Acesso em: 02 jun. 2016.

INSTITUTO DE PESQUISAS JARDIM BOTÂNICO DO RIO DE JANEIRO. Histórico. Disponível em: <http://www.jbrj.gov.br/historic/index.htm>. Acesso em: 02 jun. 2016.

JUNIOR, Cirilo. Brasil dobra áreas de preservação: total é de 8,8\% do território. Terra, Rio de Janeiro, 18 jun. 2012. Disponível em: <http://invertia.terra.com.br/sustentabilidade/rio20/noticias/0,,Ol5842996-El20323,00-

Brasil+dobra+areas+de+preservacao+total+e+de+do+territorio.html>. Acesso em: 10 set. 2012.

LIVRARIA DA FOLHA. JK achava que floresta era obstáculo ao progresso: conheça a história. Folha de São Paulo, 12 de set. de 2010. Disponível em: <http://www1.folha.uol.com.br/folha/livrariadafolha/797115-jk-achava-que-floresta-eraobstaculo-ao-progresso-conheca-a-historia.shtml>. Acesso em: 20 out. 2012.)

MAGALHÃES, Juraci Perez. A Evolução do Direito Ambiental no Brasil. 2 ed. São Paulo: Editora Juarez de Oliveira, 2002.

MEIRA, José de Castro. Direito ambiental. Informativo Jurídico da Biblioteca Ministro Oscar Saraiva, v. 19, n. 1, jan./jun., p. 11-23, 2008 . Disponível em: <http://www.stj.jus.br/publicacaoseriada/index.php/informativo/article/view/50/54>. Acesso em: 12 jan. 2013. p. 12.

MILARÉ, Édis. Direito do Ambiente. São Paulo: Revista dos Tribunais, 2001.

Direito do ambiente: doutrina, prática, jurisprudência, glossário. São Paulo: Revista dos Tribunais, 2000.

MORAES, Alexandre de. Direito constitucional. 8. ed. São Paulo: Atlas, 2000. 
Ordenações Afonsinas: livro $\quad$ V. Disponível <http://www.ci.uc.pt/ihti/proj/afonsinas/l5pg276.htm>. Acesso em: 02 jun. 2016.

Ordenações Filipinas disponíveis no site: http://www1.ci.uc.pt/ihti/proj/filipinas/l1ind.htm

PEREIRA, Rodrigo Osório. O papel dos "ilustrados" da comarca de ilhéus na regulamentação dos reais cortes de madeira: 1784-1799. In: ENCONTRO ESTADUAL DE HISTÓRIA, 3., 2006, Caetité. Anais... Caetité: $\quad$ UNEB, $2006 . \quad$ Disponível em: <http://www.uesb.br/anpuhba/artigos/anpuh_III/rodrigo_osorio.pdf>. Acesso em: 21 jan. 2013.

SÉGUIN, Elida. Direito ambiental: nossa casa planetária. 2. ed. Rio de Janeiro: Forense, 2002.

SENADO FEDERAL, <http://www2.senado.gov.br/bdsf/bitstream/id/221763/1/000750858.pdf>. Acesso em: 06 set. 2012.

SILVA, De Plácido de. Vocabulário jurídico: volume 4. 5. ed., Rio de Janeiro: Forense, 1978.

SILVA, José Afonso da. Direito ambiental constitucional. 5. ed. São Paulo: Malheiros, 2004.

SILVA, Thomas de Carvalho. O meio ambiente na constituição federal de 1988. Revista Atualidades Jurídicas, n. 8, nov./dez., p. 170-181, 2009. Disponível em: $<$ http://www.oab.org.br/editora/revista/revista_08/anexos/o_meio_ambiente_na_constitconst_fe deral.pdf>. Acesso em: 05 jan. 2013.

SIQUEIRA, Maria Isabel de. Considerações sobre ordem em colônias: as legislações na exploração do pau-brasil. CLIO - Revista de Pesquisa Histórica, v. 29, n. 1, 2011. Disponível em: <http://www.revista.ufpe.br/revistaclio/index.php/revista/article/viewFile/168/112>. Acesso em: 23 jan. 2013.

SOUZA, João Carlos de. O progresso contra a natureza: vapor, fios e trilhos em Corumbá (1904/1919). Projeto História, v. 23, p. 217-241, 2001. Disponível em:

WAINER, Ann Helen. Legislação Ambiental Brasileira: Evolução Histórica do Direito Ambiental. Revista de informação legislativa, v.30, no 118, p. 191-206, abr./jun. de 1993.

Trabalho enviado em 03 de julho de 2016.

Aceito em 17 de julho de 2016. 